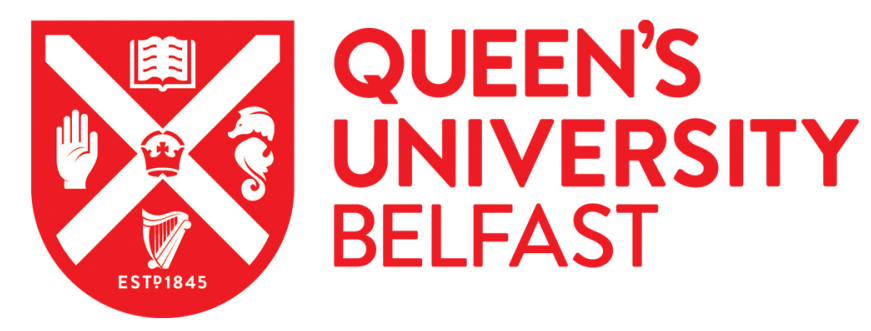

\title{
Isolated and Non-Isolated DC-to-DC Converters for Medium Voltage DC Networks: A Review
}

Alhurayyis, I., Elkhateb, A., \& Morrow, D. J. (2020). Isolated and Non-Isolated DC-to-DC Converters for Medium Voltage DC Networks: A Review. IEEE Journal of Emerging and Selected Topics in Power Electronics.

https://doi.org/10.1109/JESTPE.2020.3028057

Published in:

IEEE Journal of Emerging and Selected Topics in Power Electronics

Document Version:

Peer reviewed version

Queen's University Belfast - Research Portal:

Link to publication record in Queen's University Belfast Research Portal

Publisher rights

Copyright 2020 IEEE. This work is made available online in accordance with the publisher's policies. Please refer to any applicable terms of use of the publisher.

\section{General rights}

Copyright for the publications made accessible via the Queen's University Belfast Research Portal is retained by the author(s) and / or other copyright owners and it is a condition of accessing these publications that users recognise and abide by the legal requirements associated with these rights.

Take down policy

The Research Portal is Queen's institutional repository that provides access to Queen's research output. Every effort has been made to ensure that content in the Research Portal does not infringe any person's rights, or applicable UK laws. If you discover content in the Research Portal that you believe breaches copyright or violates any law, please contact openaccess@qub.ac.uk. 


\title{
Isolated and Non-Isolated DC-to-DC Converters for Medium Voltage DC Networks: A Review
}

\author{
Ibrahim Alhurayyis, Student Member, IEEE, Ahmad Elkhateb, Senior Member, IEEE and D John Morrow
}

\begin{abstract}
MVDC technology is a promising solution to avoid installation of new AC networks. MVDC can provide optimum integration of large-scale renewable energy sources, the interconnection of different voltage levels of DC and AC grids with the ancillary services. The development in MVDC depends significantly on the DC-DC converters. Such converters support the modern trends of utilising medium-frequency transformers in power networks. Research on isolated converters technology is in its infancy and limited by the conversion ratio and component ratings. Besides, there is no standards exist covering specific aspects of isolated converter product. Thus, a review of such converters is needed. This work presents, for the first time, a review of the DC-DC power converter families in MVDC grids including the leading families which are isolated and nonisolated converters, as well as other subfamilies comparing the specifications and characteristics. Also, the applications of these converters are provided by focusing on the essential requirements for each application.
\end{abstract}

Index Terms-MVDC grids, DC-DC power converters, dual active bridge (DAB), multilevel converter.

\section{INTRODUCTION}

$\mathbf{M}$ VDC is a promising technology in high power applications including the increased penetration of significant renewable energy sources (RESs) such as large photovoltaic $(\mathrm{PV})$, wind farms and energy storage systems (ESS) [1], [2]. Different high power DC loads, such as data centres and Electric vehicles (EVs) charging stations can be fed by direct connection to MVDC grids. That results in higher efficiency and reliability, easy controllability, and cost reduction [3], [4].

The replacement of heavy low-frequency transformers by DC-DC converters with or without galvanic isolation through medium or high-frequency transformers that enable higher operating frequency is particularly used in compacting the system footprint [2], [5]. In addition, MVDC grids facilitate lower conduction losses since they generate lower current levels than MVAC grids do [2], [6]. MVDC grids put an end to the high $\mathrm{AC}$ cables since the cross-sectional area of the cables in MVDC grids depends on the thermal limits. The DCDC converter connecting to MVDC grids compensates the line voltage drop whereas they are selected based on the maximum voltage drop to be within $\pm 5 \%$ of the output voltage in the $\mathrm{AC}$ grids [2]. MVDC grids can provide an optimal interconnection for different voltage levels of power sources and DC grids [1][7]. Thus, MVDC grids are considered as a suitable solution for grids in the distribution and collection levels with better control for the current fault and quick fault clearance which can increase the load capacity [8].

Medium voltage (MV) DC-DC converters play a prominent role in connecting a wide range of different DC systems and

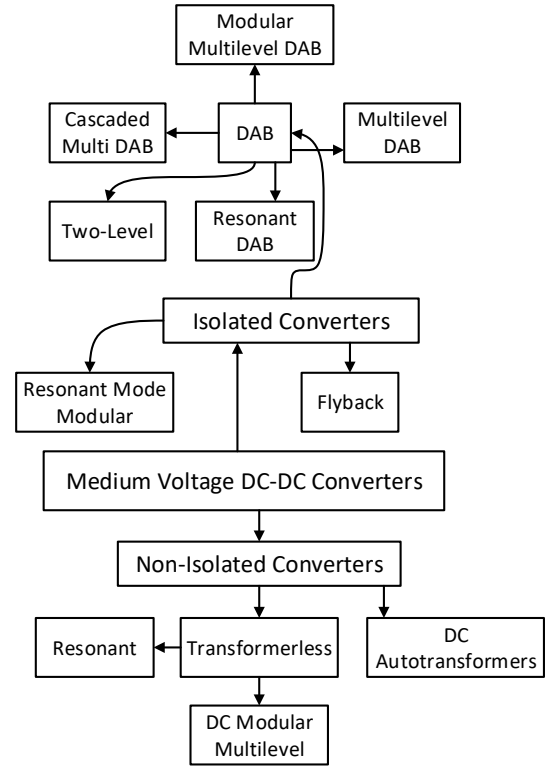

Fig. 1. The classification of MV DC-DC converters.

solid-state transformers (SSTs) [9]. Besides, they can add more functionalities to the system such as power flow control, voltage regulation, output current limiting and fast fault isolation [8]. Choosing MVDC converters is subjected to some matters that should be taken into account to ensure adequate power conversion. Such converters are required to provide high efficiency and high step-up ratio [10]. The variation in both input and output voltages should be in a specific range, and the power rate starts from tens to hundreds of megawatts. Also, the components should possess the fault-tolerant capability (FTC) to ensure high-reliability [5]. In MVDC conversion, the DC fault ride-through (FRT) capability is advantageous, especially in breaker-less systems. Three stages can achieve it: fault detection, complete de-energizing the system after identifying fault location, recovery or re-energizing after isolation the faulted part [11]. Also, the galvanic isolation is necessary to provide the safety and flexibility for the system [4], [12]. Isolation can reduce the ratings and losses of power-semiconductor devices. That leads to high efficiency and adhering to the softswitching characteristic in case of bidirectional power flow [5], [12]. However, non-isolated topologies can also provide high efficiency with zero voltage switching (ZVS) and/or zero current switching (ZCS) [6].

This work provides a review for MV DC-DC converters which are classified based on their structure, as shown in Fig. 1, and grouped to families by describing the advantages and disadvantages of each type. Furthermore, the applica- 
TABLE I

RECOMMENDED Classes For MVDC VOLTAGE

\begin{tabular}{llll}
\hline & $\begin{array}{l}\text { MVDC } \\
\text { Class }(\mathbf{k V})\end{array}$ & $\begin{array}{l}\text { Nominal Rated } \\
\text { Voltage }(\mathbf{k V})\end{array}$ & $\begin{array}{l}\text { Maximum } \\
\text { Rated Voltage } \\
(\mathbf{k V )}\end{array}$ \\
\hline Current Classes & 1.5 & 1.5 or \pm 0.75 & 2 or \pm 1 \\
& 3 & 3 or \pm 1.5 & 5 or \pm 2.5 \\
& 6 & 6 or \pm 3 & 10 or \pm 5 \\
& 12 & 12 or \pm 6 & 16 or \pm 8 \\
Future Classes & 18 & 18 or \pm 9 & 22 or \pm 11 \\
& 24 & 24 or \pm 12 & 28 or \pm 14 \\
& 30 & 30 or \pm 15 & 34 or \pm 17 \\
\hline
\end{tabular}

tions of these converters are discussed in order to identify the suitable topology for each application. The rest of this paper is structured as follows: Section II presents voltage and power rating for MVDC converters. Section III reviews the isolated converter topologies; Section IV reviews the nonisolated topologies; and Section V presents the applications, specification and characteristics of MVDC networks. Finally, Section VII draws the conclusions.

\section{RATINGS FOR MV DC/DC CONVERTERS}

The recommended classes for MVDC grids can be classified from several $\mathrm{kVs}$ to $35 \mathrm{kV}$ in DC power distribution and power-delivery systems, as shown in Table I [1]. The rating of voltage and power of the DC/DC converter depends on the application and the converter topology (isolated/non-isolated). Also, the rate varies according to the reliability of the converter topology and the switching devices.

For wind farms applications, the output of the generator should interface the input of the DC/DC converter. For offshore wind turbines, the typical output voltage of the generator is $690 \mathrm{VAC}$ [13], [14]. However, some manufacturers such as GE Power and AMSC recently starts producing generators with output voltages varying from $6.6 \mathrm{kVAC}$ to $12 \mathrm{kVAC}$. Some manufacturers have generators with higher voltage rating, such as REpower with $33 \mathrm{kVAC}$ DFIG and MHI Vestas Offshore Wind with $30 \mathrm{kV}$ and $66 \mathrm{kV}$ PMSG [15].

The input voltage of the DC/DC MVDC converter is by default the output of the rectified voltage from the wind generator or the PV farm which is in the range from $690 \mathrm{~V}$ to $66 \mathrm{kV}$. Future trends are moving towards higher voltage levels to reduce the stress on the switching devices and to decrease the conduction losses in the cables. On the other hand, the output voltage level of the converter in MVDC relies on the voltage gain that the converter can provide, in addition to the voltage ratings of the switching devices, cables and power rating of the farm. Taking into account the availability of the devices, cables and keeping the voltage gain of the converter to unity, the output voltage of MVDC converters may vary from 30 to $66 \mathrm{kV}$. It is worth noting that by keeping the voltage gain to unity, MVDC converters can still handle higher input and output voltage levels. We consider that this factor is particularly essential compared to voltage and power ratings.

The major players in offshore wind farms tend to increase the power rating to compensate the installation cost. Wind turbines generators are available from $2 \mathrm{MW}$ to $12 \mathrm{MW}$,
TABLE II

DC/DC CONVERTER RATING REQUIREMENTS

\begin{tabular}{cc}
\hline Parameters & Range \\
\hline Voltage Gain & $1 \sim 45$ \\
Power Rating & $2 \mathrm{MW} \sim 15 \mathrm{MW}$ \\
Input Voltage & $690 \mathrm{~V} \sim 66 \mathrm{kV}$ \\
Output Voltage & $30 \mathrm{kV} \sim 66 \mathrm{kV}$ \\
\hline
\end{tabular}

with $15 \mathrm{MW}$ to be installed in 2022 by Aerodyn. Table II summarizes the requirements for DC/DC converter rating [16].

\section{ISOLATED CONVERTER TOPOLOGIES}

This section studies the isolated converter topologies. The isolation usually achieved by a DC-AC-DC conversion sequence including two stages of AC-DC conversion. Coupled inductors or $\mathrm{AC}$ transformers are used for the galvanic isolation on the $\mathrm{AC}$ bus by realizing the magnetic pairing. Isolation is required for safety and grounding purposes. The isolation can protect low voltage (LV) terminals from high voltage (HV) appearing, particularly in applications demanding high ratio transformation. Isolated structures can provide different platforms of grounding in DC networks interconnection. Converters utilizing transformers are considered as different categories of the Dual Active Bridge (DAB) in terms of the similarity of DC-AC and AC-DC stages regardless of the bridge types. However, other circuits that cannot be categorized as DAB are stemmed from the flyback/forward principles.

\section{A. Dual Active Bridge}

DAB topology, shown in Fig. 2, is the most commonly used topology in MV applications offering high power density with the capability of bidirectional and soft-switching operations [17], [18]. DAB is flexible such that it can be designed for two-level (2L) converters, multilevel converters, cascaded multi DAB, modular multi DAB or even for isolated resonant converters as clarified in the following subsections.

1) Conventional $2 L D A B$ : The conventional $2 \mathrm{~L} D \mathrm{DAB}$ is composed of $2 \mathrm{~L}$ VSCs placed at the primary and secondary sides of a medium or relatively high-frequency transformer. Each bridge is formed by four switching devices [17], [19]. Phase shift modulation (PSM) by switching the crossconnected switch pairs in both bridges in turn at a fixed duty cycle allows the two full bridges to generate two $50 \%$ square voltage waveforms. The two phase-shifted voltages allow power transfer through DC-links. The magnitude and direction of the transferred power are determined by the magnitude and the sign of phase-shift angle [20].

The modulation control is a common operation for $2 \mathrm{~L}$ DAB converters due to some advantages such as easy softswitching control and low inertia. However, it results in high circulating energy if the voltage amplitude on both sides of the transformer is not similar. This happens when the step ratio $\left(V_{1} / n V_{2}\right)$ is far from 1 , where $n$ represents the transformer's ratio. As a result, the reactive circulating energy and current stress will be higher, which leads to an increase in the RMS and peak current. Also, the converter cannot be operated under 


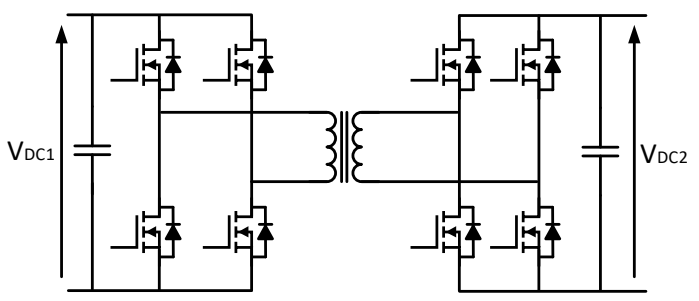

Fig. 2. The traditional DAB converter.

a wide-range of ZVS, then the power losses will be higher, and the efficiency degraded [20], [21].

Different modulation schemes have been proposed in the literature such as extended phase-shifted (EPS) [21], dual phase-shifted (DPS) [22], [23] and triple phase-shifted (TPS) modulation [20]. In EPS, the switch pairs in one bridge are switched in a similar way to SPS, whereas the switch pairs in the other bridge change their states according to an inner phase-shift ratio. That results in a three-level (3L) output AC voltage of one bridge, and the other bridge is $2 \mathrm{~L} 50 \%$ square wave [20], [21]. The outer phase-shift ratio controls the magnitude and direction of power flow, and the inner phaseshift ratio is responsible for expanding the ZVS range and reducing the circulating power and current [20], [21].

In the DPS, the cross-connected switches in both bridges are switched with a similar inner phase-shift ratio to allow both bridges generating a 3L output AC voltages [20], [22], [23]. Applying this modulation method can ensure an expanded range of ZVS, reductions in both the current stress and output capacitance, and easy implementing of deadband compensation under specific conditions compared to the SPS [20], [22], [23]. The TPS and DPS are the same, but the inner phase shift ratios are unequal [20].

The DAB converter is more preferable than other topologies in high power applications since it has the capability to achieve a zero-voltage switching (ZVS) and hence minimize the switching losses of semiconductor devices [5], [12], [17]. That leads to getting high efficiency. The use of transformer is another advantage to handle the high frequency operations with small DC-link capacitors [5], [17]. Furthermore, there is no need for a resonant capacitor because the leakage inductance of the transformer leads to smaller DC-link, and that is useful for maximizing the power transfer [5], [20].

The main drawback of DAB is the high dv/dt stresses on the AC link insulation. That can generate a current spike, and current ringing on hard switching with SiC IGBT/MOSFET switches [24]. This negatively affects the insulation, electromagnetic interference (EMI), and control signals in the isolation stage that results from the inter-winding coupling. Due to the limited degree of freedom in SPS modulation, the ZVS feature is limited [20], [21]. Furthermore, the need for active gate-driving or snubber circuits that can be used to achieve the static and dynamic balances of voltage sharing is unavoidable to reduce high switching losses [25]-[27].

2) Three-phase $D A B$ : The three-phase DAB (DAB3) is an extended multiple phase version of conventional $2 \mathrm{~L}$ DAB converter composing of 2 three-phase full bridges to form the primary and secondary sides operating based on fundamentalfrequency modulation. It provides the six-step AC voltage waveform across the centred transformer windings. The six steps mode leads to achieving the zero-voltage turn $\mathrm{ON}$ in case of inductive loads and the connected snubber capacitors among power electronic devices can result in a significant reduction in turn OFF loss [17], [20], [28]. The power is transferred as a result of phase-shifted voltages [17], [29].

Compared to some other topologies, DAB3 is preferable in high power applications due to the following advantages: the capability of transferring a significant amount of power under low root-mean-square (RMS) transformer current, high power density, low current ripple and component stress, small filter capacitors, and modularity with the capability of buck-boost functionality [30], [31]. FTC is possible since it can operate under a frozen leg mode. In this mode, the transformer current rises and then the ability to transfer power decreases [32].

On the other hand, the single-phase modulation scheme with a large phase-shift can increase RMS line currents which result in high conduction losses. Also, the non-unity voltage conversion results in high circulating current and limited softswitching range. This might negatively affect the light-load efficiency and stability among a wide range of voltages. Different advanced modulation schemes in [30] cannot completely handle the issues mentioned above. Those problems can be solved with the three-phase series resonant network for lowmedium power levels and the three-phase resonant immittance network for high power levels [30].

3) Multilevel DAB: Multilevel (ML) DAB converters, including single-phase or three-phase configurations, are needed to improve the overall performance of the conventional DAB converter. They can overcome the voltage limitation of power semiconductor switches with the capability of providing more than two voltage levels. It is worth noting that $\mathrm{ABB}$ has utilised a multilevel three-stage converter topology for a 1.2 MVA, $15 \mathrm{kV}$ SST prototype [33]. The ML DABs have low $\mathrm{dv} / \mathrm{dt}$ compared with $2 \mathrm{LDAB}$, which leads to improving the overall efficiency and high power density [24], [34], [35]. As such, converters enable LV rated devices to operate with some features such as reducing switching and conduction losses and improving FTC [19]. With a proper control scheme, the voltage stress of switches can be decreased up to the half of terminal voltage [36]. The fault-tolerant means that the system can still operate with reduced performance under the fault condition. Since the flying capacitors are used in most multilevel DC-DC converters, their voltage can be used as a diagnostic variable for short circuit fault diagnosis/detection [34], [36]. The alternative way to diagnose the fault can be achieved by using the DC-link current and the transformer?s primary side voltage as benchmarks [37]. Combining these two benchmarks with a diagnostic method of the fast switch shortcircuit fault $(\mathrm{SCF})$ is a great way to extract the characteristics of this switch immediately and then isolate the fault quickly [37]. Reducing the total transformer harmonic distortion in voltage and current waveforms is another feature resulting in lower magnetic losses in the converter [19], [38].

In medium and $\mathrm{HV}$ applications, the neutral point diode clamp (NPC) is effective for its high power density [39]. It is possible to place 3L-NPC legs on one or both sides of DAB [36], [40]-[42]. 3L NPC DAB is presented in [41] whereas the 


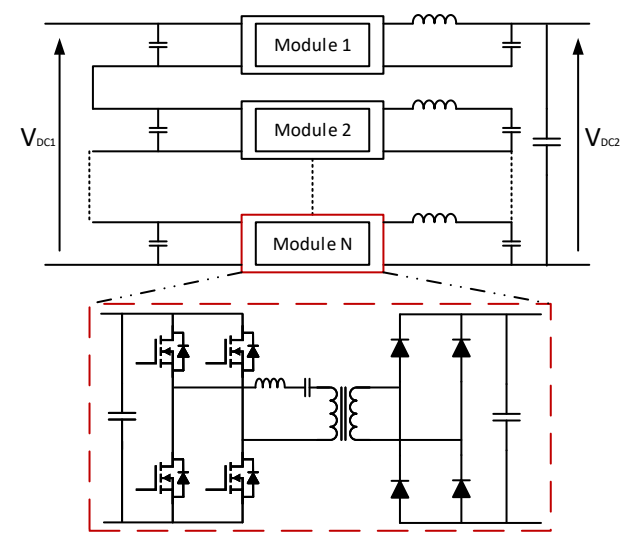

Fig. 3. Cascaded Multi DABs.

five-level DAB with NPC is proposed in [43]. The comparison of modulation schemes and components between the $3 \mathrm{~L} \mathrm{DAB}$ and the five-level DAB have been introduced in [42] operating ZVS. The advantage of $3 \mathrm{~L}$ NPC DAB is that it has high available degree of freedom to form voltage waveforms on the transformer, so it reduces switching and conduction losses [19], [44]. Also, the voltage stress of each switch in both bridges is reduced to half of the port voltage [36].

There are a few research papers on voltage balancing for multilevel converters, and the proposed solutions are all about the high switching for the fundamental frequency. This method is not suitable for NPC DABs. One method used for voltage balancing is adjusting the vectors of active voltage. This adjustment relies on measuring the imbalance voltage and power flow direction. Another technique for NPC-based full bridge utilizes a blocking capacitor for applying asymmetrical voltage pulses to the transformer side. The NPC-based full bridge has an upper and lower dc bus capacitors to generate a small voltage vector. Manipulating small voltage vectors is performed using a combination of alternative switching, and generating the neutral point current. This allows fluctuating of neutral point voltage within the selected value. Another solution can be carried out without manipulation. The optimal switching instants assigned to the inner switching pairs are shifted during the zero voltage vector interval, which enables the charging of DC capacitors regardless of the power flow direction [38]. However, the imbalance in capacitor voltage produced from the series-connected capacitors at the DC-link represents a critical challenge for multilevel NPC DAB. This is because of connecting one of the phases to the neutral point [40], [44], [45]. Although [40] provides a proper modulation and control scheme to get adequate balance in a different number of voltage levels and wide-range operating conditions, MLDABs are associated with control complexity and high number of semiconductor devices [19].

4) Cascaded Multi DAB: Multiple low-power and LV converters can be connected in series to build the MV structure in cascaded multi DABs. The series connection of LV cells can provide the desired voltage. Each cell needs an isolated DC input by using a transformer to provide galvanic isolation. This kind of topologies does not use low-frequency transformers. Thus, this converter is suitable for some applications such as PVs, batteries, and fuel cells where separated DC sources are available [46], [47]. Cascaded DABs can operate under high frequencies since cells have low ratings that lead to $\mathrm{LV}$ stress and small filter components in addition to the high power density [47]. Because each cell deals with a portion of the net power, the current rating of the devices decreases [47]. The connection of cells can be in series or parallel at the input/output side. The four possible connections are parallel input parallel output (PIPO), parallel input series output (PISO), series input parallel output (SIPO), and series input series output (SISO). PISO systems are suitable for high power high output voltage applications [48], [49] and can reduce the number of the devices if the full-bridge converter at the DAB output is replaced by a diode rectifier [50]. Fig. 3 presents a SISO converter comprising of phase-shifted fullbridge modules. Each model consists of four switches, a centred medium frequency, and diode rectifier [50].

This converter family is advantageous in terms of scalability and modularity, allowing to scale up the power and voltage ratings by utilising the same cells. In addition, it presents an acceptable performance in fault conditions as long as the fast fault current is detected [49]. The main drawbacks of this type are the high amount of switches and transformers, which lead to high conduction losses and complicated control.

5) Modular Multilevel DAB (MMC-DAB): Modular multilevel converters (MMCs) are common in medium and HV applications with more flexibility and better FTC [11], [51]. Siemens drives the development of MMCs for MVDC networks [52]. The MMC DAB converter shown in Fig. 4(a) presents a front-to-front (F2F) topology which is constructed by two MMCs through a single centre-tapped transformer for galvanic isolation with multi phases and multiple transformers. One of the MMCs imitates an AC voltage source while the other can be controlled as a current source [11], [53]. The MMC converter can be implemented using more than twophase legs as the three-phase MMC proposed in [49], [54]. The $\mathrm{AC}$ voltage is generated as a result of controlling identical submodules (SMs) in each arm of the MMC.

Different types of bridges can implement the SMs to achieve diverse functionalities. Half-bridge submodules (HBSMs) for unipolarity voltages, and full-bridge submodules (FBSMs) for bipolar voltages with better DC-fault handling are the most commonly used types [11], [53]. The efficiency of MMC based on FTF is not affected by the changes in input/ output voltage ratio and the operating power. Because of the hard-switching feature that can exist in the MMC, the operating frequency of the transformer can be restricted [5] and the total device rating (TDR) can be high, which lowers the efficiency [11]. However, this arrangement enhances the medium frequency operations, which proportionally decreases the size and weight of passive elements, hence results in high power density [11], [53]. Controlling these MMCs leads to achieving the power transfer control by the generation of two phase-shifted waveforms at the transformer sides [11], [53].

The diversity of modulation techniques such as sinusoidal, quasi-2L (Q2L), and the quasi-3L (Q3L) leads to optimum operation and size for the converter [11], [54]. Both of the Q2L and Q3L modulation [54] are used to reduce the capacitor 
value for cell capacitance requirements, DC arm inductors, and the $\mathrm{dv} / \mathrm{dt}$. That allows low-current-rating devices with better fault handling. In addition, reductions in the values of passive components and the size of the transformer is performed [55]. The transformer design working with the near-squarewaveform operation is a challenge at medium frequency (MF) [51]. FTF connection of two MMCs enables bidirectional operations, but the converter size, cost, and losses are high since the AC transformer manages the total input power.

The Hybrid MMC configurations can handle aforementioned issues with less number of semiconductor devices such as the alternate arm converter (AAC) presented in Fig. 4(b) [56]. Each arm contains FBSMs, a director switch which consists of connected switches in series and arm inductors [56], [57]. The stack of SMs takes the responsibility to generate the multistep voltage. This generated voltage based on the cell type can be positive or negative for FBSMs or only positive for HBSMs. The arm conducting the AC current is alternately determined by the director switch [56]. By using the FBSMs, only one arm is allowed to produce the AC voltage per half a cycle. Thus, the maximum voltage produced by each stack equals to $50 \%$ of the DC bus voltage and nearly half the rating of the MMC?s arm. This significantly leads to a decrease in the number of cells, and the volume and losses are reduced consequently. Using AACs, the overall system efficiency of $97.6 \%$ is achieved with a lower number of switching devices compared to MMCs [56].

The combination of $2 \mathrm{~L}$ converters (TLCs) and MMC (TLCs-MMC) [5], [58] is another example of hybrid converter that has been developed by ABB [59]. It is applicable to a wide range of power and voltage levels. The efficiency is guaranteed with small device rating and low switching losses of the semiconductor devices. That can be achieved by enabling a six-step mode operation for the TLCs in an openloop and MMC to control the transformers current in a closedloop. Particularly, it handles six-step voltages and sinusoidal currents in the AC link. The direct modulation method results in sixth-order oscillations in voltage and current. This issue can be resolved by indirect modulation. The voltage balancing of MMC can be attained using indirect modulation techniques where the circulating currents are temporarily injected to the MMC for power circulating among the arms to get voltage balancing. Injecting a DC circulating current is performed among the three-phase legs to achieve voltage balancing. Each leg has lower and upper arm and the voltage balance between them is possible through the injection of a sine circulating current. Semiconductor losses in [5] were calculated at $1.04 \%$ under full load and $1.07 \%$ under 0.1 pu load.

MMCs DAB based can take the advantages of both DAB and MMC converters such as small passive components, soft switching, and realizing FRT operation which guarantees high efficiency and power density [11]. However, the MMC DAB has double the semiconductor devices since the two full rated MMC converters are required. That results in much conduction losses and cost. This issue can be resolved by using hybrid MMC configurations. In spite of the advantages introduced for TLCsMMC, it suffers from arm capacitor voltage balancing that needs a particular balancing control method [58]. Also,

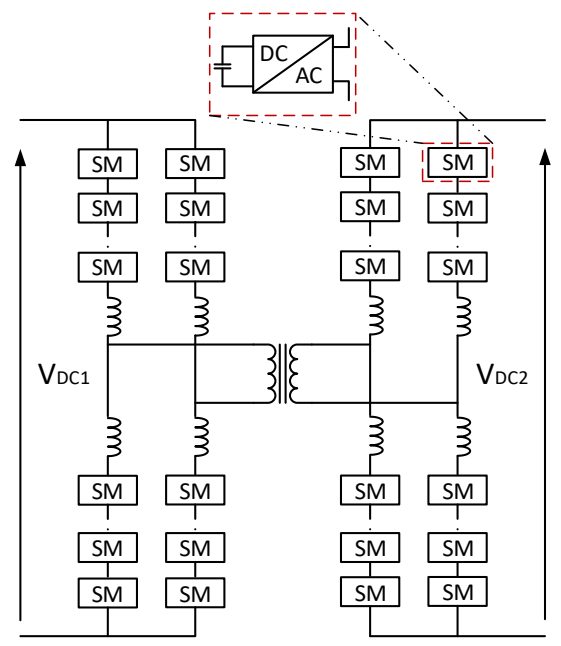

(a)

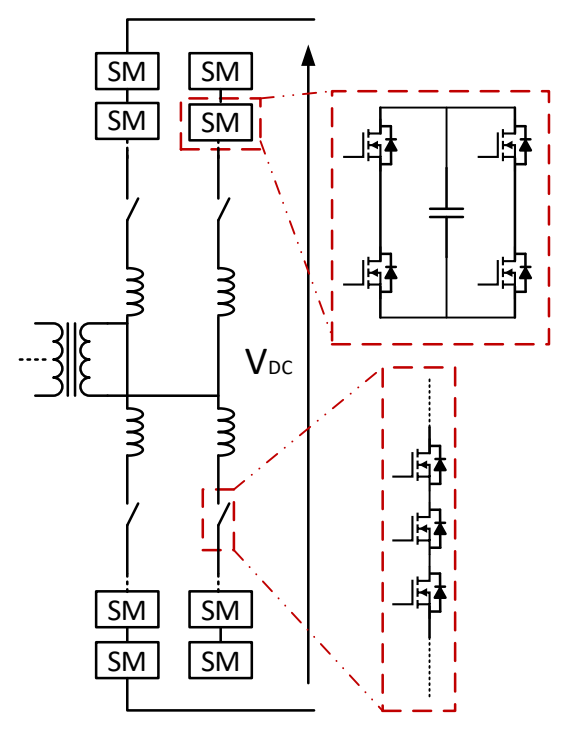

(b)

Fig. 4. MMC DAB: (a) F2F-MMCs. (b) Hybrid MMCs.

the large number of submodule capacitors are required, and it integrates three single-phase legs [5].

6) Isolated Resonant DAB: Resonant converters have great potential to shape the future of high-power conversion since they operate with high power switches and get high step-up gains with parallel resonant converters [20], [60], [61]. Typically, DC-DC conversion in resonant converters is achieved through a DC-AC-DC structure sequence [60]. DAB converter has limitations in the range of turning $\mathrm{ON}$ switching, and turning OFF that is carried out at peak current. That affects the efficiency and size of components to cope with the consequences of high current stresses. To tackle this problem, a series resonant tank can be added to DAB converter to ensure high efficiency with control flexibility as well [8], [9].

The use of the LC series resonant tank with the DAB as presented in Fig. 5 is necessary to achieve high efficiency and power density with the ZVS and ZCS for the primary and secondary sides respectively [20]. The series resonant LLC converter has been implemented in [8] with a series resonant inductor, capacitor, and shunt inductor incorporated to the 


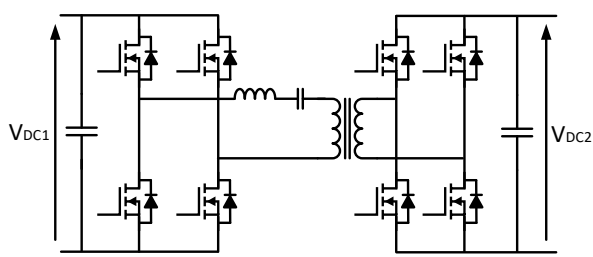

Fig. 5. Series rerter.

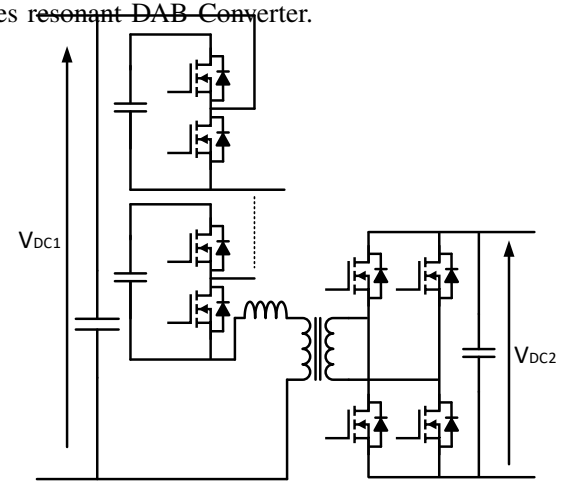

Fig. 6. Isolated resonant modular converter.

transformer magnetic inductance which can be an alternative to the conventional DAB [8], [9]. The leakage inductance has an impact on the transformer with high turns ratios which causes high overshoots through the switching semiconductors. Incorporating the leakage inductance in the resonant tanks can be beneficial in reducing losses [62]. The authors in [63] propose a CLLC resonant DAB converter with lower switching losses and better capability of transformer power delivery.

Employing the resonance tank is favourable for stepping up the voltage together with soft switching at higher power level [4], [64]. Nevertheless, the series resonant DAB converters have some drawbacks which are the extra components resulting in large size, high-cost [60], and high amount of turning OFF losses at constant frequency [62], [63].

\section{B. Isolated Resonant Mode Modular Converter (IRMMC)}

In Fig. 6 [65], the IRMMC provides a solution for the common problems inherent in non-isolated resonant converters. This problem imposes some switches and capacitors to withstand the high voltage or high current stress. At the highvoltage side, a stack of half-bridge SMs is connected to the primary winding of the transformer, and a full-bridge converter is linked to the secondary winding at the LV side. IRMMC has the advantages of the non-isolated RMMC, which are the capability of performing submodule voltage balancing and soft switching in widespread applications, in addition to the bidirectional power flow feature and the galvanic isolation. Also, this converter can be a base for different configurations to operate as a DC transformer in MVDC networks. However, the high current stress on the switches lets the IRMMC limited in terms of power rating [65].

\section{Flyback Converter Topologies}

Flyback converters are commonly used in low power applications such as smartphone chargers. They are advantageous for their light size and number of components since there is no need for an inductive output filter which results in cost reduction and high power density. Flyback converters are able to achieve different voltage levels which makes them viable for energy conversion applications [66].

In MVDC, the switching voltage stress resulting from the applied high voltage on the switches can be mitigated avoiding snubbers circuits and voltage spikes arising from turn-off switching. That can be achieved through additional units in series connection and separating the bus by inserting capacitors as the circuit in Fig. 7 [66] proposes with a simple pulse width modulation (PWM). [67] proposes a modular structure of the flyback converter applied for offshore wind power transmission. This configuration with a coupled inductor can provide a high step-down ratio with low levels of magnetic elements and could be extended to a certain number of levels and coupled inductors resulting in cost or galvanic isolation and size [66], [68]. However, conventional flyback converters are particularly designed for low power applications [68].

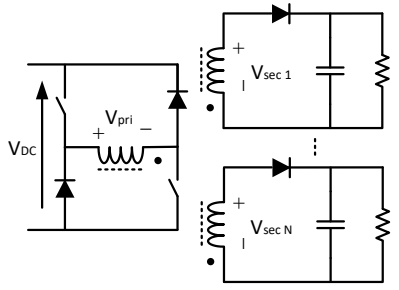

Fig. 7. Flyback converter with multiple output.

\section{Non-Isolated CONVERTER TOPOlOGiES}

The isolated topologies employ medium frequency transformers enabling switching devices at the LV side. To mitigate switching losses, the switching frequency is restrained from being low $(<1 \mathrm{kHz})$, which leads to an increase in the size of the passive components [69]. Furthermore, the design of medium-or-high-frequency transformers for high voltage and power levels purposes should ensure low core losses, better dielectric insulation and avoiding poor coupling [13], [69].

The non-isolated (transformerless) converters can eliminate the use of transformers, coupled inductors, and complicated filter circuits located at the primary and secondary terminals [69], [70]. Also, they are able to achieve high transformation ratios with less number of power semiconductor devices and low sized passive components [71]. Consequently, this option offers a solution to lower switching losses and avoid difficulties faced when designing isolation transformers and then reduces the circuit size and cost. Based on the presence of a transformer in the configuration, the non-isolated converters can be classified into two categories mainly: DC autotransformers and transformerless converters.

\section{A. DC Autotransformer Configuration}

The DC autotransformer, shown in Fig. 8, provides an alternative solution to achieve DC-AC-DC conversion with DC fault isolation and reduction in the operating cost [72]. It uses DC-AC and AC-DC frameworks (two voltage source converters) within a series connection through an $\mathrm{AC}$ transformer 


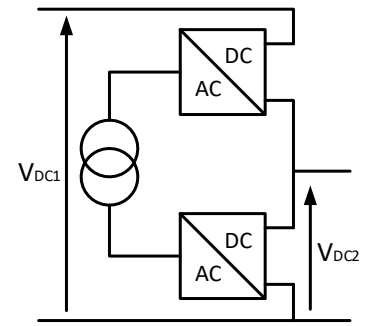

Fig. 8. DC Autotransformer Configuration.

that provides a direct electric connection without magnetic coupling. The power transferred from the input side to the output side is inverted, transferred to the second converter, and then rectified [72]. Compared to DC-AC-DC converters, DC autotransformers are capable of reducing the operating power losses to the half of the conversion losses of F2F DCDC converters which obviously results in lower operational cost i.e. $\left(V_{D C_{O}} / V_{D C_{i}}=0.5\right)$ [71], [73].

In terms of feasibility, such converter can be implemented with MVDC topologies such as two levels voltage source converter (VSC), 3L VSC, MMC, line commutated converter or diode bridge rectifiers [72]. The DC fault blocking with the MMC structure necessitates FBSMs to be installed [71]. In comparison with MMC DAB based on AC link, it can provide lower conversion losses with low rate transformer bridges [72], [73]. In addition, due to the series connection, the voltage rate of every single converter can be decreased [73]. It also has a significant investment by Siemens [71]. However, this technology is only beneficial under the low and medium stepping ratios ranges from 1.5 5 since there is no much reduction in power rate of VSCs with higher step ratios [72], [74]. Also, the power used for autotransformer converters is less than DCAC-DC converters $\left(P_{\text {auto }}=P_{D C}\left(1-V_{D C_{O}} / V_{D C_{i}}\right)\right)$ where $\left(P_{D C-A C-D C}=2 P_{D C}\right)$ [71], [72]. Compared to F2F-MMC, DC autotransformer with HBSMs can operate under the buck mode only with the lack of input DC fault blocking. Thus, for step-up mode, isolation of the bidirectional DC fault needs FBSMs, which results in high cost and heavy size [71], [74].

\section{B. Resonant based Transformerless Converters}

The DC-DC conversion in resonant based transformerless converters is achieved through a DC-AC-DC structure. In the single resonant converters, only one resonant tank is included. The LCL resonant tank in [60] is composed of two resonant inductors on both DC sides with an intermediate resonant capacitor on the AC side, whereas a single inductor is placed on the DC side of the LV converter with a centred capacitor in order to step-up the voltage [75], [76].

This converter is favourable for its soft-switching over all switches and diodes. It also eliminates the losses resulted from the reverse recovery of diodes and turning off minor carrier devices. However, high electric stresses of the passive components lead to an increase in their current and voltage ratings since there is only a single central resonant tank. Even if there is no existence for high-power transformers, the use of high-voltage high-power inductors is needed to obtain a high step-up transformation ratio. The peak-to-peak voltage among the inductor in these resonant converters is approximately the

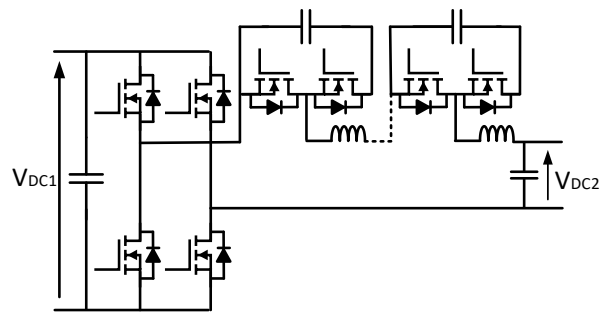

Fig. 9. Multi stages resonant converter.

double of the output voltage, while the peak-to-peak voltages in buck-boost converter are near the half of the output voltage [13]. The other aspect is the conduction losses, which can be increased since the active switches voltage stress can be equal to the output voltage, and a series diode added is essential in case of using asymmetrical switches voltage [13]. This can limit the use of these resonant converters to operate with medium transformation ratios and medium power domains. In addition, the non-modularity structure of these converters can increase the operating and maintenance costs [77].

Fig. 9 [78] shows a resonant converter with multiple stages. This converter consists of a number of HBSMs or FBSMs with the possibility to deactivate only one submodule. Replacing the central resonant tank with multiple low power resonant circuits can lead to low complexity in the design and make similar arrangement to the modular configuration [13], [78]. Both topologies are based on resonant switched-capacitor (RSC). This type of converters proposes several advantages involving modular structure, high transformation ratios, and reducing the voltage stress and switching losses of the switches.

In brief, the transformerless resonant converters come with some benefits mentioned above, but they suffer from the regulation, distribution, and balanced distribution for the semiconductor devices voltage and currents [77].

\section{DC Modular Multilevel Converters (DC-MMC)}

In MV and HV DC girds, DC-MMC converters are frequently used to achieve the desired high step-up ratio. It can be an inventive solution from the AC-DC MMC with outstanding features including modularity, scalability up to high-voltage or high-power, LV stress on the power switches, and high level of reliability by using FBSMs [79], [80]. The DC-MMCs can be classified into two topologies which are tuned-filter and push-pull. Both of them require large filter components at the output, but the tuned-filter converter requires more filtering than the push-pull type [81].

In Fig. 10, the DC-MMC converter consists of a stacked or series MMC SMs generating currents and voltages under various frequencies with the bidirectional functionality. The power is transferred between the two AC and DC loops. The DC part is responsible for the power transfer among the DC ports, while the AC part is to achieve the required balance of stored energy in the SMs [79], [80], [82]. The DC current derived by the DC voltage component allows the bidirectional power flow while the AC component leads the AC circulating current to drive the exchange of real power between the arms to achieve capacitor voltage balance [80]. The structure of the SMs affects the features of the converter. 


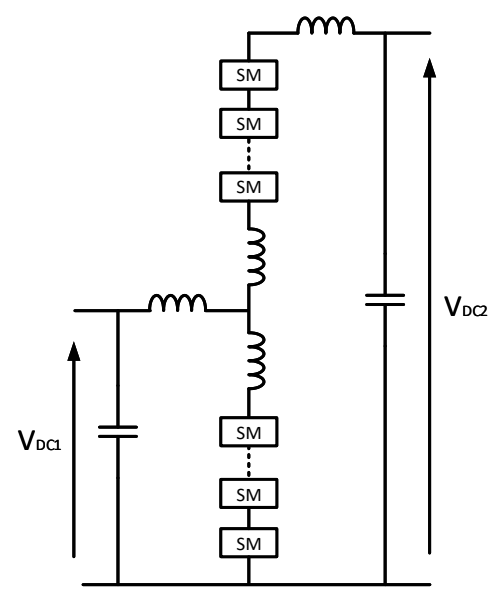

Fig. 10. DC Modular Multilevel Converter Configuration.

Using the full-bridge SMs is beneficial in terms of stepping-up and blocking fault current since they are capable of extending the maximum power and $\mathrm{AC}$ voltage component by decreasing the AC circulating current. In contrast, applying the half-bridge SMs can reduce the number of semiconductor devices, and then the high efficiency is achieved. Furthermore, it is possible to combine both types of SMs in the configuration of the converter to take their advantages [80]. Proper control methods or passive filters can keep the DC buses free from the AC component [80].

Compared to $\mathrm{DAB}, \mathrm{AC}$ component filtering in the push-pull topology needs the same amount of magnetic components that are utilized in DAB. In terms of efficiency, unlike the DAB, the DC-MMC offers higher efficiency and better performance with the unity voltage transformation ratio, where the efficiency can reach $99.5 \%$. In contrast, the efficiency drops to $95.5 \%$ when the transformation voltage is high [81].

Some hybrid configurations such as the hybrid non-isolated MMC presented in [83] provide a connection between two different DC-link voltages with a lower number of switches. It offers a low complexity since it relies on the series connection to ensure self-balancing for SMs capacitors. It is composed of a number of cascaded HBSMs connected to extra HBSMs with a series limiting resistor and shunt capacitor and a high voltage valve which consists of series-connected switches to provide excellent voltage sharing. The direction of power flow depends on the duty cycle, and semiconductor conduction results in losses under low switching frequency. Besides, the high voltage valve significantly causes switching losses coming from hard switching. Any increase in the frequency of the AC component can minimize the size of passive components and increase the switching losses.

In other aspects, the main challenge is to maintain the balance between capacitors voltages in order to achieve effective operation. The proposed converter in [83] presents a good self-balancing for capacitors voltages in the SMs. But, in hard-switching process, IGBTs form a high voltage valve that is necessary to guarantee the sharing of static and dynamic voltage among the switches. Thus, the soft switching of this valve is preferable [84].

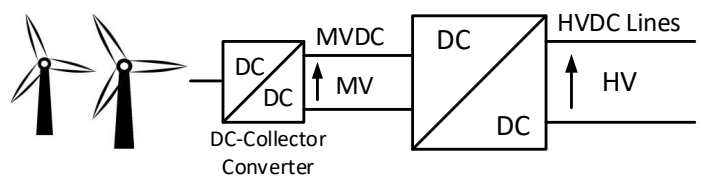

(a)

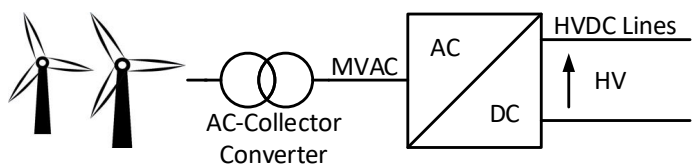

(b)

Fig. 11. Offshore wind farm collection: (a) AC collector, (b) DC collector

The DC-MMC converters are distinct from other topologies in terms of modularity, reliability, and scalability. However, large filter elements are needed, such as tuned-filter type. Also, the DC-MMC has high AC circulating current in case of high voltage transformation ratio, which leads to high conduction losses and then low efficiency. Although higher efficiency is achievable by some suitable regulation for the circulating current, MMCs are still limited to operate in a low or medium transformation ratio. That is because of the possibility of high losses that is appeared due to the AC current under high stepup transformation ratio [79].

\section{Applichtions of MVDC CONVERTERs}

Several topologies of DC-DC converters have been examined for different industrial applications. To decide a suitable topology for an application, several aspects such as step ratio, power rating, isolation, bidirectional functionality, structure, and fault blocking/ride through capability should be taken into consideration. These aspects provide a general perception of potential converters and vary in terms of importance. However, the ride through capability is required for the applications which are commonly prone to DC faults and need quick fault recoveries such as wind farms and PV MVDC collectors since the DC system has low-inertia [85], [86]. The main applications of DC-DC converters dedicated to MVDC grids will be discussed comprehensively in the following subsections with a summary shown in Table III for the critical requirements that converters should have for each application.

\section{A. DC Grids Interconnection}

MV DC-DC converters are by default the primary key for DC grid interaction applications. They link the MVDC grids to either HVDC grids or LV DC (LVDC) microgrids. As a result of the high penetration of RESs with different voltage levels, these converters and DC transmission lines get many attention [51]. The construction of MVDC grids and effective power transfer between various schemes including monopolar and bipolar MVDC grids need MV DC-DC converters for interfacing purposes [10], [87], [88]. Also, the interaction between HVDC transmission lines and MVDC distribution grids can be achieved by a converter with the characteristics of high voltage stepping-up ratio and high power ratings with FTC [5]. The bidirectional power flow capability is another possible feature that converters should have for DC grids interfaces [5], [58]. 
TABLE III

REQUIREMENTS OF DC-DC CONVERTERS FOR MVDC APPLICATIONS

\begin{tabular}{|c|c|c|c|c|c|}
\hline & DC Grids Interfacing & $\begin{array}{c}\text { DC-Collector in } \\
\text { Offshore Wind farm }\end{array}$ & PV Farms & E-Mobility & DC Transformer \\
\hline Step Ratio & Low-High [5], [71], [74] & $\begin{array}{l}\text { Medium-High } \\
\text { [79], [89] }\end{array}$ & High [90], [91] & Low-High [92] & Low-High [51], [65] \\
\hline Power & High [5] & $\begin{array}{l}\text { Medium-High [64], } \\
{[79]}\end{array}$ & High [31], [91] & Low-High [92], [93] & High [65], [94] \\
\hline Galvanic Isolation & Unnecessary [80], [83] & $\begin{array}{l}\text { Unnecessary [77], [79], } \\
\text { [82] }\end{array}$ & $\begin{array}{l}\text { Required [4], } \\
{[31],[90],[91]}\end{array}$ & Required [92], [93] & Required [65], [94] \\
\hline Bidirectional & Unnecessary [5], [58] & Unnecessary [95] & $\begin{array}{l}\text { Unnecessary } \\
{[41],[44]}\end{array}$ & Required [92], [93] & Required [65], [94] \\
\hline VSC Scheme & $\begin{array}{l}\text { Unipolar - Bipolar [10], } \\
\text { [88] }\end{array}$ & $\begin{array}{l}\text { Unipolar - Bipolar [53], } \\
\text { [82] }\end{array}$ & $\begin{array}{l}\text { Unipolar } \\
\text { Bipolar } \\
\text { [41], [44] }\end{array}$ & Unipolar [92], [93] & $\begin{array}{l}\text { Unipolar - Bipolar [51], } \\
\text { [54], [65] }\end{array}$ \\
\hline $\begin{array}{l}\text { Fault Blocking/ ride } \\
\text { through Capability }\end{array}$ & $\begin{array}{l}\text { Required, using FBSMs } \\
\text { with non-isolated convert- } \\
\text { ers [5], [71], [80], [83] }\end{array}$ & $\begin{array}{l}\text { Required, using FBSMs } \\
\text { with non-isolated con- } \\
\text { verters [82], [85] }\end{array}$ & Required [86] & Unnecessary [92], [93] & $\begin{array}{l}\text { Required [54], [65], } \\
{[94]}\end{array}$ \\
\hline
\end{tabular}

The isolated version of DC-DC converters such as MMC DAB converters is suitable for linking the MVDC to HVDC grids. This topology provides the isolation and the independency of both AC-DC stages. Thus, the fault blocking capability is guaranteed if the AC-DC is exposed to a fault. The galvanic isolation enhances the fault control process to control fault current by blocking the faulty side and allow the healthy side to maintain the current that is responsible for treating the transformer AC voltage [5], [53], [54]. Some hybrid topologies can be particularly effective in different levels of DC grids interconnection. For example, TLCs-MMC in the medium and high voltage sides provides higher efficiency for a wide range of power and input/output voltages. This converter takes the advantages of SIPO DAB and MMC converters [5], [58].

On the other side, the non-isolated versions with fault blocking capability can prevent the propagation of faults. That can be done with using FBSMs. Also, they can easily achieve interconnection with low transformation ratios. For example, in the modular configurations, DC autotransformer and DCMMC with low-MV ratios can be used to achieve interconnection with low transformation ratios [71], [74]. In addition, the non-modular non-isolated resonant can be a good choice for this purpose [71], [80], [83].

From microgrids point of view, LVDC microgrids can be connected to MVDC distribution grids [96]. SIPO configuration of the DAB family can achieve this type of interaction. Three-phase DAB (DAB3) converter with a few submodules can be enough to control the output voltage through the regulation process of a small portion of the net power transferred. That is because of the range of voltage variations which are within $\pm 5 \%$, but it suffers from the turning-off switching losses leading to limited efficiency [97]. On the other hand, the three-phase series resonant converter (SRC3) can provide some features, such as reducing the size of the capacitors of the DC-link filter and the capability of getting high power. Furthermore, the modular SRC3 converter without switching losses provides a higher efficiency compared to DAB3 converter. Thus, combining those converters as a hybrid modular converter can achieve better performance and efficiency [97]. Generally, some DAB based topologies are the most appropriate to link the MVDC grids with HVDC transmission lines and LVDC loads [2].

\section{B. Offshore Wind Farms}

Offshore wind farms with more stable wind profiles and consistent wind conditions are preferable than onshore ones in terms of high power rating. Connecting offshore wind farms to MVDC collection system leads to a low production cost of energy and expanding both the power rating of wind farms and voltage rating of the converter without limitations on generator types [13], [64]. This technology provides a promising future for offshore wind farms applications by eliminating the additional conversion stages and getting better system reliability [79], [95]. MVDC collection system is composed of MV ACDC, DC-DC converters, and MVDC bus. Fig. 11(a) shows the standard AC collector that can be replaced by a DC collector [98]. The DC collection system presented in Fig. 11(b) [13], [98] significantly depends on DC-DC converters in boosting the output voltages of the wind turbines and connecting the MV bus to the HVDC lines [13], [76], [98].

The features of high-gain voltage and high power should be considered in terms of selecting the DC-DC converter in this application, since the converter are used to boost the voltage generated by wind turbines [64], [89], [98]. In addition, reliability is an important issue because of the difficulty in getting access to the turbine at sea and transporting equipment to installation sites [77].

Cascaded multilevel DAB with galvanic isolation feature and PIOS configuration can ensure current sharing, stepup operation, and better fault handling [99]. Also, hybrid modular multilevel DAB converters with unipolar or bipolar arrangement may be accepted for offshore wind farms [53], [57]. Regardless of the high stepping-up transformation ratio, the modular structure can still operate under a reduced level of power if one module fails. The fault can be detected easily, which leads to easier maintenance and then better reliability [77]. Thus, the DC-MMCs would be a better choice for offshore wind farms in MVDC systems [77], [79]. A good example of this type is the DC-MMC with a simple unipolar structure presented in [82]. Also, the non-modular options with a low number of resonant elements to achieve the highstep gains and soft switching can increase the operational and 
TABLE IV

MV ISOLATED DC-DC CONVERTERS CHARACTERISTICS

\begin{tabular}{|c|c|c|c|c|c|}
\hline Topology & Advantages & Disadvantages & Application & Voltage Ratio & Power Rate \\
\hline $\begin{array}{l}2 \mathrm{~L} \\
\mathrm{DAB}\end{array}$ & $\begin{array}{l}\text { 1) High efficiency with ZVS. 2) Less total } \\
\text { device ratings. 3) High frequency Operation. } \\
\text { 4) Small DC-link capacitor. [5], [12], [17] }\end{array}$ & $\begin{array}{l}\text { 1) High dv/dt stresses on } \mathrm{AC} \\
\text { link insulation. 2) The need for } \\
\text { snubber circuits or active gate- } \\
\text { driving. [24]-[27]. }\end{array}$ & $\begin{array}{l}\text { E-Mobility. } \\
{[100]}\end{array}$ & $\begin{array}{l}\text { Depends on DC } \\
\text { step ratio and } \\
\text { switch connect. } \\
{[5],[20]}\end{array}$ & $\begin{array}{l}\text { Low-High } \\
\text { [12], [17], } \\
\text { [24]. }\end{array}$ \\
\hline $\begin{array}{l}\text { Three- } \\
\text { phase } \\
\text { DAB }\end{array}$ & $\begin{array}{l}\text { 1) High power transfer. 2) Small size filter } \\
\text { capacitor. 3) Better FTC due to frozen leg } \\
\text { mode. [30], [32] }\end{array}$ & $\begin{array}{l}\text { 1) High induction losses with } \\
\text { single-phase modulation. 2) } \\
\text { High circulating current. [30] }\end{array}$ & $\begin{array}{l}\text { 1) DC grids intercon- } \\
\text { nection [97] 2) PV ap- } \\
\text { plications [31] 3) E- } \\
\text { Mobility [92], [100]. }\end{array}$ & $\begin{array}{l}\text { Depends on DC } \\
\text { step ratio and } \\
\text { switches series } \\
\text { connect. [30] }\end{array}$ & $\begin{array}{l}\text { High [29], } \\
{[30] .}\end{array}$ \\
\hline $\begin{array}{l}\text { Multilevel } \\
\text { DAB }\end{array}$ & $\begin{array}{l}\text { 1) Low dv/dt compared with } 2 \mathrm{~L} \text { DAB [24], } \\
\text { [34], [35]. 2) Less total device ratings (TDR) } \\
\text { [19]. 3) LV stress up to } 50 \% \text { of the input } \\
\text { voltage [36]. 4) Better FTC [36], [101]. 5) } \\
\text { Lower THD [19], [38]. }\end{array}$ & $\begin{array}{l}\text { 1) Imbalance in DC-link capac- } \\
\text { itors voltage [40], [44], [45]. } \\
\text { 2) Control complexity. 3) High } \\
\text { number of semiconductor de- } \\
\text { vices. [19] }\end{array}$ & $\begin{array}{l}\text { 1) PV applications } \\
[41], \quad[44] . \quad 2) \text { DC } \\
\text { Transformers [94]. }\end{array}$ & $\begin{array}{l}\text { Depends } \\
\text { on modules } \\
\text { connection }[42] .\end{array}$ & High [43]. \\
\hline $\begin{array}{l}\text { Cascaded } \\
\text { Multi } \\
\text { DAB }\end{array}$ & $\begin{array}{l}\text { 1) Operating under high frequencies. 2) LV } \\
\text { stress. 3) Low filter components. [47], [50] }\end{array}$ & $\begin{array}{l}\text { 1) Many components. 2) Com- } \\
\text { plicated control. 3) High con- } \\
\text { duction losses. [46], [48] }\end{array}$ & $\begin{array}{l}\text { 1) Offshore wind [99] } \\
\text { 2) PV [47] 3) DC } \\
\text { Transformers [94] }\end{array}$ & $\begin{array}{l}\text { Depends on mod- } \\
\text { ules number and } \\
\text { connection [46], } \\
{[48]}\end{array}$ & $\begin{array}{l}\text { Medium- } \\
\text { High [46], } \\
{[48]}\end{array}$ \\
\hline $\begin{array}{l}\text { Resonant } \\
\text { DAB }\end{array}$ & $\begin{array}{l}\text { 1) Soft switching \& high frequency [8], [9], } \\
\text { [17], [20], [63]. 2) High efficiency [4], [63]. } \\
\text { 3) Bidirectional Power flow [20], [63]. 4) } \\
\text { Control flexibility [8], [9] }\end{array}$ & $\begin{array}{l}\text { Extra components result in } \\
\text { large size }[8],[9],[60] .\end{array}$ & E-Mobility [92], [100] & $\begin{array}{l}\text { Medium-High } \\
{[20]}\end{array}$ & $\begin{array}{l}\text { Medium- } \\
\text { High [62] }\end{array}$ \\
\hline IRMMC & $\begin{array}{l}\text { 1) Soft switching. 2) Inherent voltage bal- } \\
\text { ancing of SMs. [65] }\end{array}$ & High current stresses [65]. & DC transformers [65] & $\begin{array}{l}\text { Depends on step } \\
\text { ratio and connec- } \\
\text { tion [65] }\end{array}$ & High [65] \\
\hline Flyback & Modularity and multilevel [66], [68]. & Auxiliary circuits [66], [68]. & Offshore wind [67] & Low [66] & Low [66] \\
\hline
\end{tabular}

maintenance (O\&M) costs [76], [77], [79]. That is because of the high losses.

It is noted that the capability of bidirectional power flow is unnecessary for the wind farm DC collectors [95]. DC autotransformer cannot be an alternative option since it loses its features in the high transformer ratio [72], [74]. Flyback converters are not suitable for DC collection because of the disability to operate in medium-high power applications even though the work in [67] proposed them for offshore wind power transmission.

\section{Photovoltaic Farms}

Currently, MVAC grids are the platform for collecting the photovoltaic (PV) farms. That can lead to instability, and multi-resonance resulted from the parallel-connection of inverters. To provide high-efficiency conversion and a lightweight system, MVDC collection with HVDC transmission can joint numerous DC sources. A better option is using high step-up ratio DC-DC converters to transfer the generated electrical power from the lower output voltage of PV module [90]. These converters should be able to deal with high voltage and high power capacity as well. They should provide high step-up ratio, electrical isolation, FTC, high efficiency and high power density, and implement the maximum-power-point tracking (MPPT) [4], [86], [91], [102]-[105]. Also, galvanic isolation can fairly well reduce insulation requirements and components stress which fulfils the safety requirements [4], [91].
Multilevel DAB with PISO structure is considerably used for integrating PV farms into MVDC grids to enhance the total power and attain the high voltage gain. The 3L NPC based DAB is an excellent option for applications with 300 $\mathrm{V}$ to 1500 voltage range because of the simple structure and operation [41], [44]. Additionally, the 3-phase DAB can be another selection due to high power capacity and low size filter requirements with soft-switching capability [31]. Thus, cascaded multilevel and 3-phase DAB converters are preferable for PV applications because of the capability of electrical isolation, soft switching, and broad operating range.

\section{E-Mobility (EVs and Railway Systems)}

The electrified transportation field requires the DC system for reliable integration. The integration of EVs with power systems results in energy exchange, and that leads to increase in employing DC devices [106], [107]. The increased use of EVs demands fast-charging stations [92], [108]. The EV charging stations (EVCSs) can be connected to MVDC bus through MV DC-DC converters. The converter used for this purpose should have the ability of bidirectional power flow since it is connected to ESS [109], [110]. Moreover, galvanic isolation is necessary to isolate the grid voltage. Resonant converters have a great interest in charging applications [111]. Therefore, the isolated DAB family essentially the $2 \mathrm{~L} D A B$, three-phase $\mathrm{DAB}$, or resonant $\mathrm{DAB}$ can be a proper solution for charging infrastructure since it comes with high output current and galvanic isolation [92], [100]. 
TABLE V

MV NON-ISOLATED DC-DC CONVERTERS CHARACTERISTICS

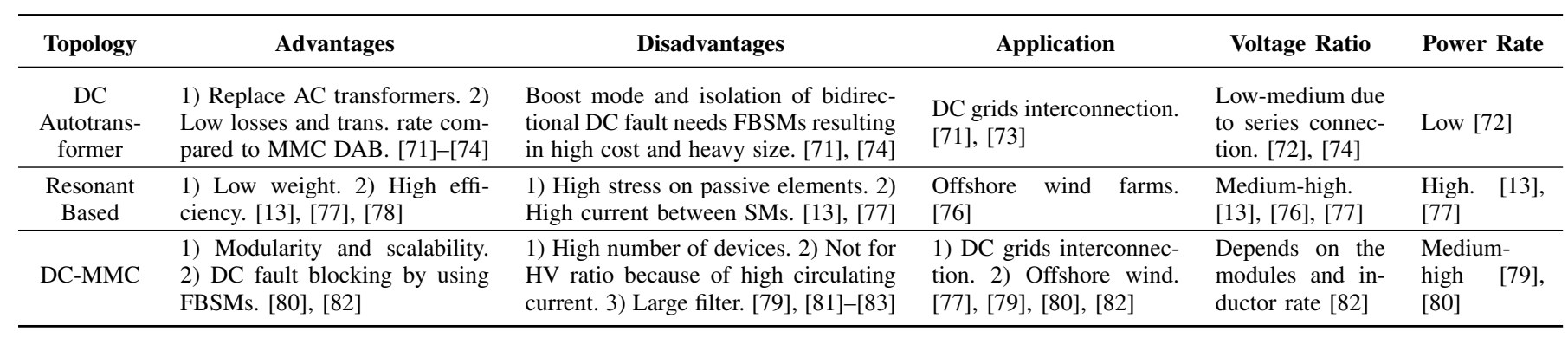

The electrified MVDC railway system has been an excellent option replacing conventional AC railway systems. Such railways have properly uninterrupted high-speed moves, simple catenary networks, and effortless connections to DC sources such as PV arrays [112]. Therefore, the multilevel DAB3 topology with galvanic isolation is an appropriate converter to feed railway substations in MVDC networks [93].

\section{E. DC Transformers (DCTs)}

In DC grids, interconnecting different DC links is possible through a DC tap or DC transformer. That includes two connection types. The first type is the connection scheme between two MVDC distribution grids with a small difference in voltage levels which is classified as a low step-ratio interface [65]. The second one is a high stepratio connection that links the MVDC grids to the LVDC microgrids.

DCTs with the bidirectional power flow feature are appreciated as a better solution to compensate the faults in the MVDC or LVDC buses. This solution provides high reliability to the system since it can replace the faulted cell while the system is running normally. DCTs with the bidirectional power flow also enables the rapid electrical disconnection between the MVDC and LVDC buses in case of external faults occurrence [94].

MMC DAB family is well suited for the DC transformer since it can tackle the high power high step-ratio DC conversions [51], [54], [65], [94]. In addition, multilevel DABs and cascaded multi DABs can link LVDC grids to MVDC grids with electrical isolation and fault management [94]. However, a great number of different switches in multilevel DABs results in complicated control to get the voltage balancing. Also, using cascaded multilevel DABs may bring some difficulties such as isolation challenges and voltage balancing initiating from using several transformers. That leads to a reduction in efficiency and reliability [65].

The isolated resonant modular converter provides a solution for the challenges mentioned above because of its softswitching characteristics and high transformation ratio. Thus, this converter would be a potential solution for DC taps or transformers in MVDC networks [51], [54], [65].

\section{FUTURE TRENDS IN MVDC-DC CONVERTERS}

There is a massive number of DC-DC converter topologies, but only a few have been particularly studied for MVDC networks. The upcoming MV DC-DC converters should bear in mind the following features: low overall losses, compact size and low cost, high operating temperature for power semiconductor devices, and better DC fault management.

Multi-terminal direct current (MTDC) networks represent the future of smart grids with different multiple large scale energy sources [71], [113]. That leads to the development of multi-port DC-DC converters (MPCs) to connect these resources. A good example is proposed in [113], which combines two different topologies, NPC and the DAB. This combination can manage the power among three-generation systems, including a PV panel, fuel cell, and battery.

Regarding semiconductor power devices, the current silicon carbide $(\mathrm{SiC})$ semiconductor devices have been adopted in many configurations. The SiC-based solutions come with a significant reduction in size which is two-third in the volume and up to half of the weight, and better cooling requirements compared to Si-based modules. They can provide a higher breakdown voltage with lower on-state resistance and faster switching speed. Thus, the recent $\mathrm{SiC}$ MOSFETs and $\mathrm{SiC}$ IGBTs with $>10 \mathrm{kV}$ rating may omit the cascaded structure in MV high power applications [9], [114].

\section{CONCLUSION}

This work provides a detailed review for DC-DC converters that can be applied in MVDC applications. Based on their structures, the classification has been made by proposing the advantages and disadvantages for each type to effectively identify the suitable topology for DC-DC conversion in MVDC networks. The distinctive characteristics for each topology are summarized in Table IV and Table V. The summary includes advantages, disadvantages, suitable applications, voltage step ratio, and power rating.

Based on the main classifications, the galvanic isolation is necessary for the high step-up voltage ratio since it offers better utilization for switching device and reducing the circulating reactive power. On the contrary, the non-isolated topologies can be limited to low-medium transformation ratios to avoid the high AC current that also increases the losses.

Recently, the resonant and modular structures are getting the attention since they offer high efficiency and reliability paving the way for the adoption of MV in the modern power system. It can be notable that both DAB and MMC families are the most suitable topologies with the features of bi-directionality and galvanic isolation in DABs, and modularity in MMCs. They provide almost all requirements for medium-voltage DC systems. In addition, some converters combining both topologies are presented, such as hybrid converters to find a 
solution for some problems or particular usages that incorporate bidirectional power transfer and high transformation ratio.

From the comprehensive analysis, it can be concluded that the optimal topology for MVDC networks should combine the merits of modularity, bidirectional power flow, and galvanic isolation to meet the required voltage and improve the overall efficiency. All these characteristics can reduce the size, decrease the losses, and provide better fault management. Even though the modular designs require many semiconductor devices, the recent development in semiconductor devices that enable high blocking voltage can significantly reduce the number of components and reduce the cost offering impressive performance. To end the controversy, each topology discussed in the text would be an addition to integrating MVDC grids optimally, but some of them are unique and obtain most of the requirements mentioned above.

For DC grids interconnection, the converter should present the fault blocking capability. The hybrid versions, especially TLCs-MMC can effectively link the MVDC to HVDC grids while the modular SRC3 converter is well suited for connecting LVDC grids. In offshore wind farms, the converter must be able to cope with high voltage gains and high power, such as PIOS DABs or DC-MMC for the low to MV ratio. For PV applications, cascaded DAB with PISO structure or 3-phase DAB can achieve all PV requirements. Bidirectionality is an essential feature for converters designed for EV applications. $\mathrm{DAB}$ family is a preferable choice, such as $2 \mathrm{~L}$ DAB or three-phase DAB. For future DC transformers, some published works proposed the MMC DAB based, cascaded multi DABs, and the isolated resonant modular converter for this particular application.

\section{REFERENCES}

[1] "IEEE recommended practice for $1 \mathrm{kV}$ to $35 \mathrm{kV}$ medium-voltage dc power systems on ships," IEEE Std 1709-2018, pp. 1-54, Dec. 2018.

[2] M. Stieneker and R. De Doncker, "Medium-voltage dc distribution grids in urban areas," in Proc. IEEE 7th Int. Symp. Power Electron. Distrib. Gener. Syst., Jun. 2016, pp. 1-7.

[3] M. Stojadinovic and J. Biela, "Comparison of high power non-isolated multilevel dc-dc converters for medium-voltage battery storage.." in Proc. 17th Eur. Conf. Power Electron. Appl., Sep. 2015, pp. 1-10.

[4] R. Suryadevara and L. Parsa, "Full-bridge zcs-converter-based highgain modular dc-dc converter for pv integration with mvdc grids," IEEE Trans. Energy Convers., vol. 34, no. 1, pp. 302-312, Mar. 2019.

[5] S. Cui, N. Soltau, and R. De Doncker, "A high step-up ratio softswitching dc-dc converter for interconnection of mvdc and hvdc grids," IEEE Trans. Power Electron., vol. 33, no. 4, pp. 2986-3001, Apr. 2018.

[6] M. Abbasi and J. Lam, "A step-up transformerless, zv-zcs high-gain $\mathrm{dc} / \mathrm{dc}$ converter with output voltage regulation using modular step-up resonant cells for dc grid in wind systems," IEEE Trans. Emerg. Sel. Topics Power Electron., vol. 5, no. 3, pp. 1102-1121, Sep. 2017.

[7] P. Simiyu et al., "Review of the dc voltage coordinated control strategies for multi-terminal vsc-mvdc distribution network," The Journal of Engineering, vol. 2019, no. 16, pp. 1462-1468, 2019.

[8] M. Agamy et al., "A high power medium voltage resonant dual active bridge for mvdc ship power networks," IEEE Trans. Emerg. Sel. Topics Power Electron., vol. 5, no. 1, pp. 88-99, Mar. 2017.

[9] L. Wang, Q. Zhu, W. Yu, and A. Huang, "A medium-voltage mediumfrequency isolated dc-dc converter based.." IEEE Trans. Emerg. Sel. Topics Power Electron., vol. 5, no. 1, pp. 100-109, Mar. 2017.

[10] S. Cui et al., "A modular multilevel converter with a zigzag transformer for bipolar mvdc distribution systems," IEEE Trans. Power Electron. vol. 34, no. 2, pp. 1038-1043, Feb. 2019.
[11] Y. Shi and H. Li, "Isolated modular multilevel dc-dc converter with dc fault current control capability based on current-fed dual active bridge for mvdc application," IEEE Trans. Power Electron., vol. 33, no. 3, pp. 2145-2161, Mar. 2018.

[12] L. Zhu, "A novel soft-commutating isolated boost full-bridge ZVSPWM dc-dc converter for bidirectional high power applications," IEEE Trans. Power Electron., vol. 21, no. 2, pp. 422-429, Mar. 2006.

[13] W. Chen, A. Huang, C. Li, G. Wang, and W. Gu, "Analysis and comparison of medium voltage high power dc/dc converters for offshore wind energy systems," IEEE Trans. Power Electron., vol. 28, no. 4, pp. 2014-2023, Apr. 2013.

[14] "World's most powerful offshore wind turbine: Haliade-x 12 mw: Ge renewable energy." [Online]. Available: https://www.ge.com/

[15] "Wind turbines database," En.wind-turbine-models.com.

[16] "Scd-technology scd nezzy: Scd-technology (super compact drive)," Aerodyn-engineering.com.

[17] R. De Doncker, D. Divan, and M. Kheraluwala, "A three-phase softswitched high-power-density dc/dc converter for high-power applications," IEEE Trans. Ind Appl., vol. 27, no. 1, pp. 63-73, Jan. 1991.

[18] F. Krismer and J. Kolar, "Efficiency-optimized high-current dual active bridge converter for automotive applications," IEEE Trans. Ind. Electron., vol. 59, no. 7, pp. 2745-2760, Jul. 2012.

[19] A. Martinez, S. Monge, J. Apruzzese, and J. Bordonau, "Operating principle and performance optimization of a three-level npc dual-activebridge dc-dc converter," IEEE Trans. Ind. Electron., vol. 63, no. 2, pp. 678-690, Feb. 2016

[20] B. Zhao, Q. Song, W. Liu, and Y. Sun, "Overview of dual-active-bridge isolated bidirectional dc-dc converter for high-frequency-link powerconversion system," IEEE Trans. Power Electron., vol. 29, no. 8, pp. 4091-4106, Aug. 2014.

[21] B. Zhao, Q. Yu, and W. Sun, "Extended-phase-shift control of isolated bidirectional dc-dc converter for power distribution," IEEE Trans. Power Electron., vol. 27, no. 11, pp. 4667-4680, Nov. 2012.

[22] H. Bai and C. Mi, "Eliminate reactive power and increase system efficiency of isolated bidirectional dual-active-bridge dc-dc converters using novel dual-phase-shift control," IEEE Trans. Power Electron., vol. 23, no. 6, pp. 2905-2914, Nov. 2008.

[23] B. Zhao, Q. Song, W. Liu, and W. Sun, "Current-stress-optimized switching strategy of isolated bidirectional dc-dc converter with dualphase-shift control," IEEE Trans. Ind. Electron., vol. 60, no. 10, pp. 4458-4467, Oct. 2013.

[24] A. Tripathi et al., "Design considerations of a $15 \mathrm{kV}$ SiC IGBT-based medium-voltage high-frequency isolated dc-dc converter," IEEE Trans. Ind Appl., vol. 51, no. 4, pp. 3284-3294, Jul. 2015.

[25] A. Kadavelugu and S. Bhattacharya, "Design considerations and development of gate driver for $15 \mathrm{kV}$ sic igbt," in Proc. IEEE Applied Power Electron. Conf. Expo., Mar. 2014, pp. 1494-1501.

[26] S. Hazra et al., "Design considerations and performance evaluation of $1200 \mathrm{~V} 100 \mathrm{~A}$ sic mosfet-based two-level voltage source converter," IEEE Trans. Ind Appl., vol. 52, no. 5, pp. 4257-4268, Sep. 2016.

[27] S. Madhusoodhanan et. al, "Solid-state transformer and MV grid tie applications enabled by $15 \mathrm{kV} \mathrm{SiC}$ igbts and $10 \mathrm{kV} \mathrm{SiC}$ mosfets based multilevel converters," IEEE Trans. Ind Appl., vol. 51, no. 4, pp. 33433360, Jul. 2015.

[28] E. De Din et al., "Voltage control of parallel-connected dual-active bridge converters for shipboard applications," IEEE Trans. Emerg. Sel. Topics Power Electron., vol. 6, no. 2, pp. 664-673, 2018.

[29] S. Engel, N. Soltau, H. Stagge, and R. De Doncker, "Dynamic and balanced control of three-phase high-power dual-active bridge dc-dc converters in dc-grid applications," IEEE Trans. Power Electron., vol. 28 , no. 4, pp. 1880-1889, 2013.

[30] A. Khan and K. Loo, "A three-phase dual-active-bridge dc-dc converter with reconfigurable resonant network for efficient wide voltage range," IEEE Trans. Power Electron., vol. 35, no. 2, pp. 1322-1339, 2020.

[31] J. Hu et al., "A maximum-output-power-point-tracking-controlled dualactive bridge converter for pv energy integration into mvdc grids," IEEE Trans. Energy Convers., vol. 34, no. 1, pp. 170-180, Mar. 2019.

[32] M. Berger, I. Kocar, H. Fortin-Blanchette, and C. Lavertu, "Open-phase fault-tolerant operation of the three-phase dual active bridge converter," IEEE Trans. Power Electron., vol. 35, no. 4, pp. 3651-3662, 2020.

[33] D. Dujic et al., "Power electronic traction transformer-low voltage prototype," IEEE Trans. Power Electron., vol. 28, no. 12, pp. 55225534, 2013.

[34] P. Liu, C. Chen, and S. Duan, "An optimized modulation strategy for the three-level dab converter with five control degrees of freedom," IEEE Trans. Ind. Electron., vol. 67, no. 1, pp. 254-264, 2020. 
[35] S. Kouro et al., "Recent advances and industrial applications of multilevel converters," IEEE Trans. Ind. Electron., vol. 57, no. 8, pp. 2553-2580, Aug. 2010.

[36] P. Liu, C. Chen, S. Duan, and W. Zhu, "Dual phase-shifted modulation strategy for the three-level dual active bridge dc-dc converter," IEEE Trans. Ind. Electron., vol. 64, no. 10, pp. 7819-7830, Oct. 2017.

[37] X. Pei, S. Nie, and Y. Kang, "Switch short-circuit fault diagnosis and remedial strategy for full-bridge dc-dc converters," IEEE Trans. Power Electron., vol. 30, no. 2, pp. 996-1004, 2015.

[38] M. Awal et al., "Capacitor voltage balancing for neutral point clamped dual active bridge converters," IEEE Trans. Power Electron., vol. 35 , no. 10 , pp. $11267-11276,2020$.

[39] L. Franquelo et al., "The age of multilevel converters arrives," IEEE Ind. Electron. Magazine, vol. 2, no. 2, pp. 28-39, Jun. 2008.

[40] A. Filba-Martinez, S. Busquets-Monge, and J. Bordonau, "Modulation and capacitor voltage balancing control of multilevel npc dual active bridge dc-dc converters," IEEE Trans. Ind. Electron., vol. 67, no. 4, pp. 2499-2510, Apr. 2020.

[41] M. Moonem and H. Krishnaswami, "Control and configuration of threelevel dual-active bridge dc-dc converter as a front-end interface for pv system," in Proc. IEEE Applied Power Electron. Conf. Expo., Mar. 2014, pp. 3017-3020.

[42] R. Burkart and J. Kolar, "Comparative $\eta-\rho-\sigma$ pareto optimization of si and sic multilevel dual-active-bridge topologies with wide input," IEEE Trans. Power Electron., vol. 32, no. 7, pp. 5258-5270, Jul. 2017.

[43] M. Moonem and H. Krishnaswami, "Analysis and control of multi-level dual active bridge dc-dc converter," in Proc. IEEE Energy Convers. Congr. Expo., Sep. 2012, pp. 1556-1561.

[44] J. Lee, H. Choi, and J. Jung, "Three level npc dual active bridge capacitor voltage balancing switching modulation," in Proc. IEEE Int. Telecommun. Energy Conf., Oct. 2017, pp. 438-443.

[45] M. Moonem, T. Duman, and H. Krishnaswami, "Capacitor voltage balancing in a neutral-point clamped multilevel dc-dc dual active bridge converter," in Proc. IEEE 8th Int. Symp. Power Electron. Distrib. Gener. Syst., Apr. 2017, pp. 1-7.

[46] P. Zumel et al., "Modular dual-active bridge converter architecture," IEEE Trans. Ind Appl., vol. 52, no. 3, pp. 2444-2455, May 2016.

[47] Y. Shi, "Modular current-fed dual-active-bridge dc-dc converters for medium voltage system applications," Ph.D. dissertation, Florida State University, Tallahassee, 2016. [Online]. Available: https: //diginole.lib.fsu.edu/islandora/object/fsu\%3A405684/

[48] W. Chen, X. Ruan, H. Yan, and C. Tse, "Dc/dc conversion systems consisting of multiple converter modules: Stability, control.." IEEE Trans. Power Electron., vol. 24, no. 6, pp. 1463-1474, Jun. 2009.

[49] R. Xie and H. Li, "Fault performance comparison study of a dual active bridge (dab) converter and an isolated modular multilevel dc/dc (im2dc) converter for power conversion module application in a breaker-less.." IEEE Trans. Ind Appl., vol. 54, no. 5, pp. 5444-5455, 2018.

[50] Q. Wei, B. Wu, D. Xu, and N. Zargari, "Model predictive control of capacitor voltage balancing for cascaded modular dc-dc converters," IEEE Trans. Power Electron., vol. 32, no. 1, pp. 752-761, Jan. 2017.

[51] X. Xiang et al., "A compact modular multilevel dc-dc converter for high step-ratio MV and hv use," IEEE Trans. Ind. Electron., vol. 65, no. 9, pp. 7060-7071, Sep. 2018.

[52] "Mvdc plus I solutions I global," new.siemens.com.

[53] S. Kenzelmann et al., "Isolated $\mathrm{dc} / \mathrm{dc}$ structure based on modular multilevel converter," IEEE Trans. Power Electron., vol. 30, no. 1, pp. 89-98, Jan. 2015.

[54] I. Gowaid et al., "Quasi two-level operation of modular multilevel converter for use in a high-power dc transformer with dc fault isolation," IEEE Trans. Power Electron., vol. 30, no. 1, pp. 108-123, 2015.

[55] _ - "Analysis and design of a modular multilevel converter with trapezoidal modulation for medium and high voltage dc-dc.." IEEE Trans. Power Electron., vol. 30, no. 10, pp. 5439-5457, Oct. 2015.

[56] M. Merlin et al., "The alternate arm converter: A new hybrid multilevel converter with dc-fault blocking capability," IEEE Trans. Power Del., vol. 29 , no. 1 , pp. 310-317, 2014.

[57] T. Lüth et al., "High-frequency operation of a dc/ac/dc system.." IEEE Trans. Power Electron., vol. 29, no. 8, pp. 4107-4115, 2014.

[58] S. Cui, J. Hu, and R. De Doncker, "Control and experiment of a tlcmmc hybrid dc-dc converter for the interconnection of mvdc and hvdc," IEEE Trans. Power Electron., vol. 35, no. 3, pp. 2353-2362, 2020.

[59] "Hvdc light it's time to connect," ABB Library.

[60] D. Jovcic, "Bidirectional, high-power dc transformer," IEEE Trans. Power Del., vol. 24, no. 4, pp. 2276-2283, Oct. 2009.
[61] S. Inoue and H. Akagi, "A bidirectional isolated dc-dc converter as a core circuit of the next-generation medium-voltage power conversion," IEEE Trans. Power Electron., vol. 22, no. 2, pp. 535-542, Mar. 2007.

[62] C. Dincan et al., "Analysis of a high-power, resonant dc-dc converter for dc wind turbines," IEEE Trans. Power Electron., vol. 33, no. 9, pp. 7438-7454, Sep. 2018.

[63] D. Dong et al., "A modular $\mathrm{SiC}$ high-frequency solid-state transformer for medium-voltage applications: Design, implementation, and testing," IEEE Trans. Emerg. Sel. Topics Power Electron., vol. 7, no. 2, pp. 768778, Jun. 2019.

[64] L. Shu et al., "A resonant zvzcs dc-dc converter with two uneven transformers for an mvdc collection system of offshore wind farms,' IEEE Trans. Ind. Electron., vol. 64, no. 10, pp. 7886-7895, Oct. 2017.

[65] X. Xiang, X. Zhang, G. Chaffey, and T. Green, "An isolated resonant mode modular converter with flexible modulation and variety of configurations for mvdc application," IEEE Trans. Power Del., vol. 33, no. 1, pp. 508-519, Feb. 2018.

[66] K. Leandro et al., "A high input voltage and high step-down ratio double-ended flyback converter," in Proc. 13th Brazilian Power Electron. Conf., Nov. 2015, pp. 1-6.

[67] Y. Hu et al., "Design of a modular, high step-up ratio dc-dc converter for hvdc applications integrating offshore wind power," IEEE Trans. Ind. Electron., vol. 63, no. 4, pp. 2190-2202, 2016.

[68] M. Pagliosa, R. Faust, T. Lazzarin, and I. Barbi, "Input-series and output-series connected modular single-switch flyback converter operating in the discontinuous conduction mode," IET Power Electron., vol. 9, no. 9, pp. 1962-1970, 2016.

[69] H. Athab, A. Yazdani, and B. Wu, "A transformerless dc-dc converter with large voltage ratio for mv dc grids," IEEE Trans. Power Del., vol. 29, no. 4, pp. 1877-1885, Aug. 2014.

[70] S. Du et al., "A novel medium-voltage modular multilevel dc-dc," IEEE Trans. Ind. Electron., vol. 63, no. 12, pp. 7939-7949, Dec. 2016.

[71] G. Kish, "On the emerging class of non-isolated modular multilevel dc-dc converters for dc and hybrid ac-dc systems," IEEE Trans. Smart Grid, vol. 10, no. 2, pp. 1762-1771, 2019.

[72] W. Lin, "Dc-dc autotransformer with bidirectional dc fault isolating capability," IEEE Trans. Power Electron., vol. 31, no. 8, pp. 54005410, Aug. 2016.

[73] A. Schön and M. Bakran, "Average loss calculation and efficiency of the new hvdc autotransformer," in Proc. 16th Eur. Conf. Power Electron. Appl., Aug. 2014, pp. 1-10.

[74] W. Lin, J. Wen, L. Yao, and B. Yang, "Step-up unidirectional dc-dc autotransformer for hvdc applications," in Proc. IEEE 8th Int. Power Electron. and Motion Control Conf., May 2016, pp. 703-707.

[75] D. Jovcic, "Step-up dc-dc converter for megawatt size applications," IET Power Electron., vol. 2, no. 6, pp. 675-685, Nov. 2009.

[76] J. Robinson, D. Jovcic, and G. Joos, "Analysis and design of an offshore wind farm using a MVDC grid," IEEE Trans. Power Del., vol. 25, no. 4, pp. 2164-2173, Oct. 2010.

[77] A. Parastar, Y. Kang, and J. Seok, "Multilevel modular dc/dc power converter for high-voltage dc-connected offshore wind energy," IEEE Trans. Ind. Electron., vol. 62, no. 5, pp. 2879-2890, May 2015.

[78] Y. Li, X. Lyu, and D. Cao, "A zero-current-switching high conversion ratio modular multilevel dc-dc converter," IEEE Trans. Emerg. Sel. Topics Power Electron., vol. 5, no. 1, pp. 151-161, 2017.

[79] A. Gandomkar, A. Parastar, and J. Seok, "High-power multilevel stepup $\mathrm{dc} / \mathrm{dc}$ converter for offshore wind energy systems," IEEE Trans. Ind. Electron., vol. 63, no. 12, pp. 7574-7585, Dec. 2016.

[80] H. Yang, M. Saeedifard, and A. Yazdani, "An enhanced closed-loop control strategy with capacitor voltage elevation for the dc-dc modular multilevel converter," IEEE Trans. Ind. Electron., vol. 66, no. 3, pp. 2366-2375, Mar. 2019.

[81] S. Engel et al., "Comparison of the modular multilevel dc converter and the dual-active bridge converter for power conversion.." IEEE Trans. Power Electron., vol. 30, no. 1, pp. 124-137, Jan. 2015.

[82] X. Zhang and T. Green, "The modular multilevel converter for high step-up ratio dc-dc conversion," IEEE Trans. Ind. Electron., vol. 62, no. 8, pp. 4925-4936, 2015.

[83] A. Elserougi, A. Massoud, I. Abdelsalam, and S. Ahmed, "Selfbalanced non-isolated hybrid modular dc-dc converter for mvdc grids," IET Gener. Transm. Distrib., vol. 12, no. 15, pp. 3626-3636, 2018.

[84] — "Modular multilevel dc-dc converter with arm interchange.." IET Gener. Transm. Distrib., vol. 14, no. 4, pp. 564-576, 2020.

[85] B. Novakovic and A. Nasiri, "Modular multilevel converter for wind energy storage applications," IEEE Trans. Ind. Electron., vol. 64, no. 11, pp. $8867-8876,2017$. 
[86] X. Xinze et al., "Dc transformer requirements and fault operation analysis in pv medium voltage dc power collection system," The Journal of Engineering, vol. 2019, no. 18, pp. 4788-4793, 2019.

[87] F. Mura and R. De Doncker, "Design aspects of a medium-voltage direct current mvdc grid for a university campus," in Proc. 8th Int. Conf. Power Electron., May 2011, pp. 2359-2366.

[88] L. Sun et al., "A transformerless bidirectional dc-dc converter based on power units with unipolar and bipolar structure for mvdc interconnection," in Proc. Int. Power Electron. Conf., May 2018, pp. 2882-2886.

[89] G. Ning et al., "A hybrid resonant zvzcs three-level converter for mvdcconnected offshore wind power collection systems," IEEE Trans. Power Electron., vol. 33, no. 8, pp. 6633-6645, Aug. 2018

[90] — - "Hybrid resonant zvzcs pwm full-bridge converter for large pv parks connecting to mvdc grids," IEEE Trans. Emerg. Sel. Topics Power Electron., vol. 5, no. 3, pp. 1078-1090, Sep. 2017.

[91] S. Lu et al., "A high step-up modular isolated dc-dc converter for large capacity pv generation system integrated into mvdc grids," in Proc. 10th Int. Conf. Power Electron. and ECCE, May 2019, pp. 1915-1920.

[92] M. Stieneker et al., "Mvdc distribution grids for electric vehicle fastcharging infrastructure," in Proc. Int. Power Electron. Conf., May 2018, pp. 598-606.

[93] A. Hinz, M. Stieneker, and R. De Doncker, "Impact and opportunities of medium-voltage dc grids in urban railway systems," in Proc. 18th Eur. Conf. Power Electron. Appl., Sep. 2016, pp. 1-10.

[94] B. Zhao et al., "Full-process operation, control, and experiments of modular high-frequency-link dc transformer based on dual active bridge for flexible mvdc distribution: A practical tutorial," IEEE Trans. Power Electron., vol. 32, no. 9, pp. 6751-6766, 2017.

[95] H. Liu et al., "Design and control of unidirectional dc-dc modular multilevel converter for offshore dc collection point: Theoretical analysis and experimental validation," IEEE Trans. Power Electron., vol. 34, no. 6, pp. 5191-5208, Jun. 2019.

[96] Q. Song, B. Zhao, J. Li, and W. Liu, "An improved dc solid state transformer based on switched capacitor and multiple-phase-shift shootthrough modulation for integration of lvdc energy storage system and mvdc distribution grid," IEEE Trans. Ind. Electron., vol. 65, no. 8, pp. 6719-6729, Aug. 2018.

[97] J. Hu et al., "A partial-power regulated hybrid modular dc-dc converter to interconnect mvdc and LVDC grids," in Proc. IEEE 10th Int. Symp. Power Electron. Distrib. Gener. Syst., Jun. 2019, pp. 1030-1035.

[98] L. Bourserie et al., "Power hardware in-the-loop validation of dc-dc power converter for offshore wind energy," in 21st Eur. Conf. Power Electron. Appl., 2019, pp. 1-10.

[99] M. Guan, "A series-connected offshore wind farm based on modular dual-active-bridge (dab) isolated dc-dc converter," IEEE Trans. Energy Convers., vol. 34, no. 3, pp. 1422-1431, 2019.

[108] G. Reed, B. Grainger, A. Sparacino, and Z. Mao, "Ship to grid: Medium-voltage dc concepts in theory and practice," IEEE Power and Energy Mag., vol. 10, no. 6, pp. 70-79, Nov. 2012.
[100] L. Gill et al., "Medium voltage dual active bridge using $3.3 \mathrm{kv}$ sic mosfets for ev charging application," in IEEE Energy Convers. Congr. Expo., 2019, pp. 1237-1244.

[101] H. Sheng, F. Wang, and C. Tipton IV, "A fault detection and protection scheme for three-level dc-dc converters based on monitoring flying capacitor voltage," IEEE Trans. Power Electron., vol. 27, no. 2, pp. 685-697, 2012.

[102] A. El Khateb, N. Rahim, J. Selvaraj, and B. Williams, "Dc-todc converter with low input current ripple for maximum pv power extraction," IEEE Trans. Ind. Electron., vol. 62, no. 4, pp. 2246-2256, 2015.

[103] A. El Khateb, N. Rahim, J. Selvaraj, and M. Uddin, "Fuzzy-logiccontroller-based sepic converter for maximum power point tracking," IEEE Trans. Ind Appl., vol. 50, no. 4, pp. 2349-2358, 2014.

[104] A. Elkhateb, N. Rahim, J. Selvaraj, and M. N. Uddin, "Maximum power point tracking of single-ended primary-inductor converter employing a novel optimisation technique for proportional-integralderivative controller," IET Power Electron., vol. 6, no. 6, pp. 11111121, 2013.

[105] A. Elkhateb, N. Rahim, J. Selvaraj, and B. Williams, "The effect of input current ripple on the photovoltaic panel efficiency," in IEEE Conf. Clean Energy and Tech., 2013, pp. 478-481.

[106] C. Liu, K. Chau, D. Wu, and S. Gao, "Opportunities and challenges of vehicle-to-home, vehicle-to-vehicle, and vehicle-to-grid technologies," Proceedings of the IEEE, vol. 101, no. 11, pp. 2409-2427, Nov. 2013.

[107] M. Yilmaz and P. Krein, "Review of the impact of vehicle-to-grid technologies on distribution systems and utility interfaces," IEEE Trans. Power Electron., vol. 28, no. 12, pp. 5673-5689, Dec. 2013.

[109] P. Triviño, J. Torreglosa, L. Ramírez, and F. Jurado, "Decentralized fuzzy logic control of microgrid for electric vehicle charging station," IEEE Trans. Emerg. Sel. Topics Power Electron., vol. 6, no. 2, pp. 726-737, Jun. 2018

[110] P. Triviño, L. Ramírez, J. Torreglosa, and F. Jurado, "Control of electric vehicles fast charging station supplied by pv/energy storage system/grid," in Proc. IEEE Int. Energy Conf., Apr. 2016, pp. 1-6.

[111] A. Elkhateb, G. Adam, and D. Morrow, "Dc-to-dc converter topologies for wireless power transfer in electric vehicles," in 45th Annи. Conf. IEEE Ind. Electron., vol. 1, 2019, pp. 1665-1669.

[112] X. Zhu, H. Hu, H. Tao, and Z. He, "Stability analysis of pv plant-tied mvdc railway electrification system," IEEE Trans. Transport. Electrific, vol. 5, no. 1, pp. 311-323, Mar. 2019.

[113] P. Kolahian, H. Tarzamni, A. Nikafrooz, and M. Hamzeh, "Multi-port dc-dc converter for bipolar medium voltage dc micro-grid applications," IET Power Electron., vol. 12, no. 7, pp. 1841-1849, 2019.

[114] B. Passmore and C. O'Neal, "High-voltage sic power modules for 1025 kv applications," Power Electron. Eur. Mag, no. 1, pp. 22-24, 2016 